\title{
On the pathogenesis of penile venous leakage: role of the tunica albuginea
}

\author{
Ahmed Shafik*1, Ismail Shafik ${ }^{1}$, Olfat El Sibai ${ }^{2}$ and Ali A Shafik ${ }^{1}$
}

Address: ${ }^{1}$ Department of Surgery and Experimental Research, Faculty of Medicine, Cairo University, Cairo, Egypt and ${ }^{2}$ Department of Surgery, Faculty of Medicine, Menoufia University, Shebin El-Kom, Egypt

Email: Ahmed Shafik* - shafik@ahmedshafik.com; Ismail Shafik - shafik@ahmedshafik.com; Olfat El Sibai - shafik@ahmedshafik.com; Ali A Shafik - shafik@ahmedshafik.com

* Corresponding author

Published: 5 September 2007

BMC Urology 2007, 7:14 doi:10.1 186/147|-2490-7-14
Received: 16 January 2007

Accepted: 5 September 2007

This article is available from: http://www.biomedcentral.com/I47/-2490/7//4

(C) 2007 Shafik et al; licensee BioMed Central Ltd.

This is an Open Access article distributed under the terms of the Creative Commons Attribution License (http://creativecommons.org/licenses/by/2.0), which permits unrestricted use, distribution, and reproduction in any medium, provided the original work is properly cited.

\begin{abstract}
Background: Etiology of venogenic erectile dysfunction is not exactly known. Various pathologic processes were accused but none proved entirely satisfactory. These include presence of large venous channels draining corpora cavernosa, Peyronie's disease, diabetes and structural alterations in fibroblastic components of trabeculae and cavernous smooth muscles. We investigated hypothesis that tunica albuginea atrophy with a resulting subluxation and redundancy effects venous leakage during erection.
\end{abstract}

Methods: 18 patients (mean age $33.6 \pm 2.8$ SD years) with venogenic erectile dysfunction and 17 volunteers for control (mean age 31.7 \pm 2.2 SD years) were studied. Intracorporal pressure was recorded in all subjects; tunica albuginea biopsies were taken from 18 patients and 9 controls and stained with hematoxylin and eosin and Masson's trichrome stains.

Results: In flaccid phase intracorporal pressure recorded a mean of $1 \mathrm{I} .8 \pm 0.8 \mathrm{~cm} \mathrm{H}_{2} \mathrm{O}$ for control subjects and for patients of $5.2 \pm 0.6 \mathrm{~cm}$, while during induced erection recorded $98.4 \pm 6.2$ and $5.9 \pm 0.7 \mathrm{cmH}_{2} \mathrm{O}$, respectively. Microscopically, tunica albuginea of controls consisted of circularlyoriented collagen impregnated with elastic fibers. Tunica albuginea of patients showed degenerative and atrophic changes of collagen fibers; elastic fibers were scarce or absent.

Conclusion: Study has shown that during erection intracorporal pressure of patients with venogenic erectile dysfunction was significantly lower than that of controls. Tunica albuginea collagen fibers exhibited degenerative and atrophic changes which presumably lead to tunica albuginea subluxation and floppiness. These tunica albuginea changes seem to explain cause of lowered intracorporal pressure which apparently results from loss of tunica albuginea venoocclusive mechanism. Causes of tunica albuginea atrophic changes and subluxation need to be studied.

\section{Background}

Many classifications have been proposed for erectile dysfunction (ED) [1]. A common classification of ED, which integrates the various causes of impotence with the under- standing of erectile physiology and functional anatomy, comprises psychogenic, neurogenic, arteriogenic, venogenic, and endocrinologic origin $[1,2]$. Failure of adequate venous occlusion has been proposed as one of the most 
common causes of venogenic impotence [3]. The cause of veno-occlusive dysfunction is not exactly known. It may result from several possible pathophysiologic processes which include the presence of large venous channels draining the corpora cavernosa, Peyronie's disease, diabetes and structural alterations in the fibroelastic components of the trabeculae, cavernous smooth muscle and endothelium [4-6].

The treatment of venogenic ED (VED) is penile veins ligation if the known less invasive measures such as intracavernous injection of vasodilators fail to induce adequate erection [7]. It seems that these treatment modalities deal with a secondary effect rather than the primary etiological factor of the venogenic ED; therefore the results of treatment are unsatisfactory [7]. We hypothesized that the cause of venous leakage during erection is an atrophy of the tunica albuginea (TA) with a resulting TA subluxation and redundancy. This hypothesis was investigated in the current study.

\section{Methods \\ Subjects}

The study comprised 18 patients (mean age of $33.6 \pm 2.8$ SD years, range 30-36) with VED of a mean duration of 7.4 SD years (4-10). They gave a history of erectile dysfunction lasting for a mean of $2.4 \pm 0.6$ minutes (range 2-3). Clinical examination including neurologic was unremarkable. The endocrine profile was normal. The patients demonstrated a normal response to penile biothesiometry and normal resting penile brachial indices (PBI) as determined by Doppler ultrasound. Nocturnal penile testing established impaired erectile function. Dynamic infusion cavernosometry and cavernosography demonstrated an incompetent veno-occlusive mechanism.

Seventeen subjects were included in the study as controls. Their ages matched the patients' age (mean $31.7 \pm 2.2 \mathrm{SD}$ years, range 29-33). Eight of the 17 subjects had a normal penis while seven had a degloved penis and a torn TA resulting from motor car accidents, and two subjects had penile squamous cell carcinoma involving only the skin of the penis and not encroaching on the TA. All of the control subjects gave a history of normal erection. The history and investigations of all of the studied subjects showed that they had no medical conditions nor were under drug regimens that could cause ED. A consent was given by the subjects to be studied after they had been informed about the nature of the study and the investigations to be done for them. The study was approved by the Cairo University Faculty of Medicine Review Board and Ethics Committee.

\section{Methods}

The intracorporal pressure (ICP) of the 18 subjects with VED and 17 control subjects was recorded by an angi- ocatheter (Gould Inc, Cleveland, OH). The pressure was measured in the flaccid phase and after inducing erection by intracorporal injection of papaverine in a dose of 60 $\mathrm{mg}$. The catheter was introduced into the corpora cavernosa (CC) and connected to pneumohydraulic capillary infusion system (Arndorfer Medical Specialties, Greendale, WI), the pump of which delivered saline solution continuously via the capillary tube at a rate of $0.6 \mathrm{ml} / \mathrm{min}$. The transducer outputs were registered on a rectilinear recorder (Model RS-3400, Gould Inc, Cleveland, OH). Occlusion of the recording orifice produced a pressure elevation rate that was greater than $250 \mathrm{cmH}_{2} \mathrm{O} / \mathrm{s}$. To ensure reproducibility of the results, the pressure in each individual was measured at least twice and the mean value was calculated.

During operative interference, TA biopsies measuring 0.3 $\times 0.3 \mathrm{~cm}$ were taken from the subjects with VED and from those with traumatically torn TA and penile carcinoma. They were obtained from the TA on the lateral aspect of the penis, and from the same location in patients and controls. The specimens were fixed in $10 \%$ buffered formalin, dehydrated in graded alcohol and processed for histologic examination. Tissues were embedded in paraffin, sectioned at $4 \mu \mathrm{m}$ and then stained with hematoxylin and eosin and Masson's trichrome stains. The latter stains collagen and elastin blue and smooth muscles red. Photomicrographs were obtained, developed and digitized with $16.7 \times 10^{6}$ colors at a resolution of $1.024 \times 768$ on a scanner.

The results of the study were analyzed statistically using the SPSS (statistical package for the social sciences, version 10) to determine the analysis of variance (ANOVA) and Student's $t$ test. Values were given as the mean $\pm \mathrm{SD}$. Differences assumed significance at $\mathrm{p}<0.05$.

\section{Results}

The study was completed in all the subjects without adverse side effects. The ICP in the flaccid phase of the control subjects ( 8 normal subjects) recorded a mean of $11.8 \pm 0.8 \mathrm{cmH}_{2} \mathrm{O}$ and of the patients with VED $5.2 \pm 0.8$ $\mathrm{cmH}_{2} \mathrm{O}$, while during induced erection for the control subjects a mean of $98.4 \pm 6.2 \mathrm{~cm} \mathrm{H}_{2} \mathrm{O}$ was registered (table 1). For the patients with VED, erection was maintained for a mean period of $2.4 \pm 0.6 \mathrm{~min}$ (range 1-3) during which the intracorporal pressure recorded a mean of $65.2 \pm 4.8 \mathrm{cmH}_{2} \mathrm{O}$; after this period detumescence occurred and the ICP recorded a mean of $5.9 \pm 0.7 \mathrm{cmH}_{2} \mathrm{O}$ (table 1).

Microscopic study of the TA of 9 of the 17 control subjects ( 7 with torn TA, 2 with penile squamous cell carcinoma) revealed that it consisted of excessive collagen impregnated with elastic fibers (Fig. 1). The collagen fibers were 
Table I: The intracorporal pressure of the 8 control subjects and 18 patients with venogenic erectile dysfunction (VED) in the flaccid and erectile phases ${ }^{+}$

\begin{tabular}{lllll}
\hline & \multicolumn{2}{l}{ Intracorporal pressure } \\
& VED patients & \multicolumn{2}{l}{ Control subjects } \\
& Mean & Range & Mean & Range \\
\hline & & & & \\
\hline $\begin{array}{l}\text { Flaccid phase } \\
\text { Erectile Phase } \\
\text { |st 2.4 min } \\
\quad \text { Later }\end{array}$ & $5.2 \pm 0.8^{*}$ & $4-6$ & $11.8 \pm 0.8$ & $10-13$ \\
& $65.2 \pm 4.8^{*}$ & $52-79$ & $98.4 \pm 6.2$ & $92-106$ \\
\hline
\end{tabular}

+ values were given as the mean \pm SD

$* p<0.05$

** $\mathrm{p}<0.001$

$P$ values of patients with VED were compared with those of the control subjects

circularly oriented in all the specimens. In 7 specimens, the circularly arranged collagen fibers were associated with longitudinally arranged collagen fibers (Fig. 2).
Microscopic examination of the biopsies from the 18 patients with VED showed degenerative changes and atrophy of the collagen fibers (Fig. 3). The circular arrangement of the collagen fibers was lost and the fibers were irregularly oriented. The collagen fibers in some specimens were fragmented (Fig. 4) while the elastic fibers were either scarce or completely absent in the specimens

\section{Discussion}

The current study may shed some light on the pathogenesis of VED. The venules that drain the sinusoidal spaces and the smooth muscles of the penis coalesce as they approach the CC periphery and form the subtunical venular plexus [8]. Small veins exit from the plexus through the TA as the emissary veins, and drain into the circumflex veins or directly into the deep dorsal vein. The position of the subtunical venular plexus between the sinusoids and TA allows for their compression and occlusion as the smooth muscle and sinusoids relax and expand against the TA during tumescence [8-11]. This occlusion acts to

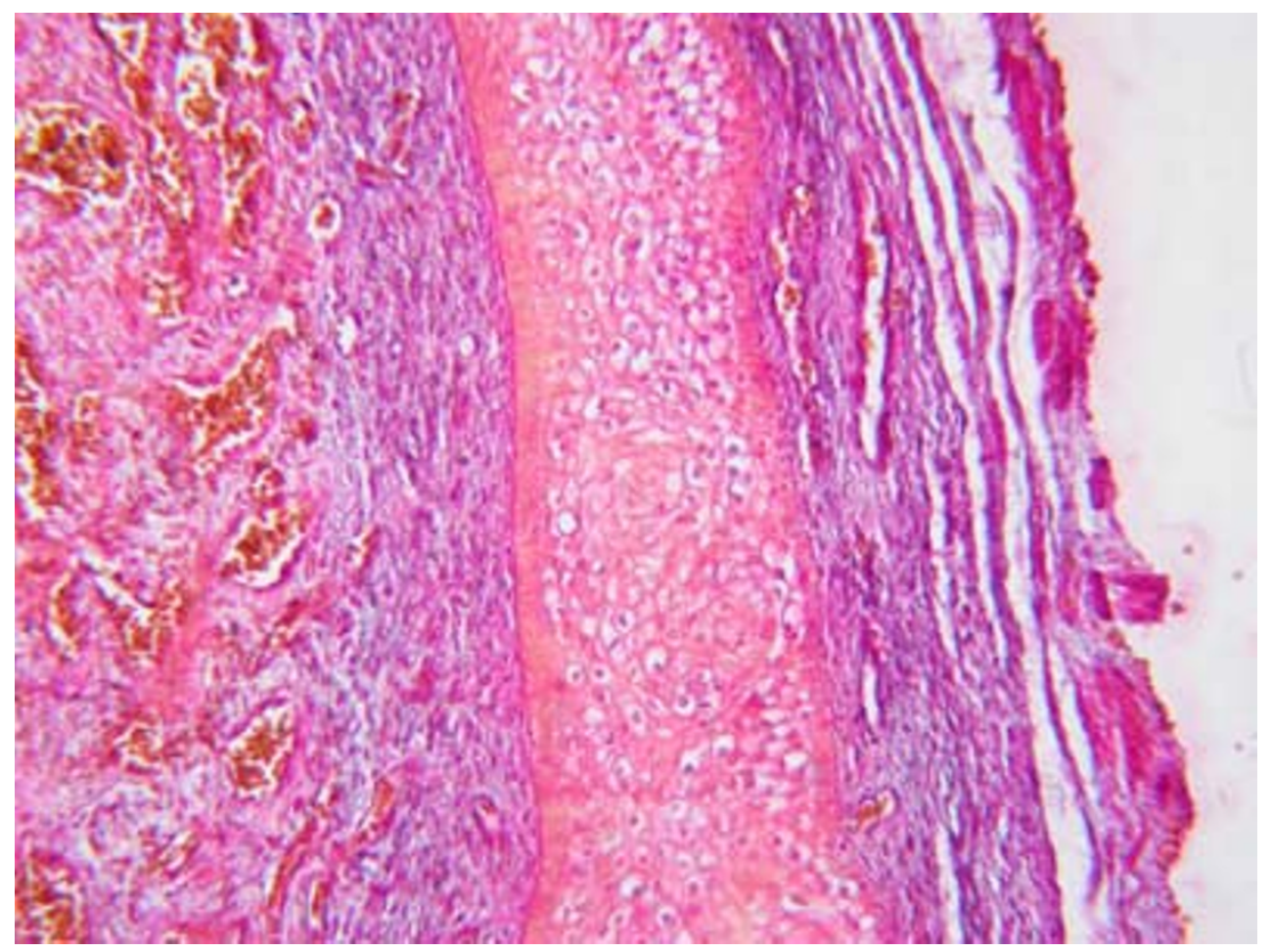

\section{Figure I}

Photomicrograph of tunica albuginea of control subject showing that it consists of collagen impregnated with few elastic fibers (Masson's trichrome stain $\times 400$ ). 


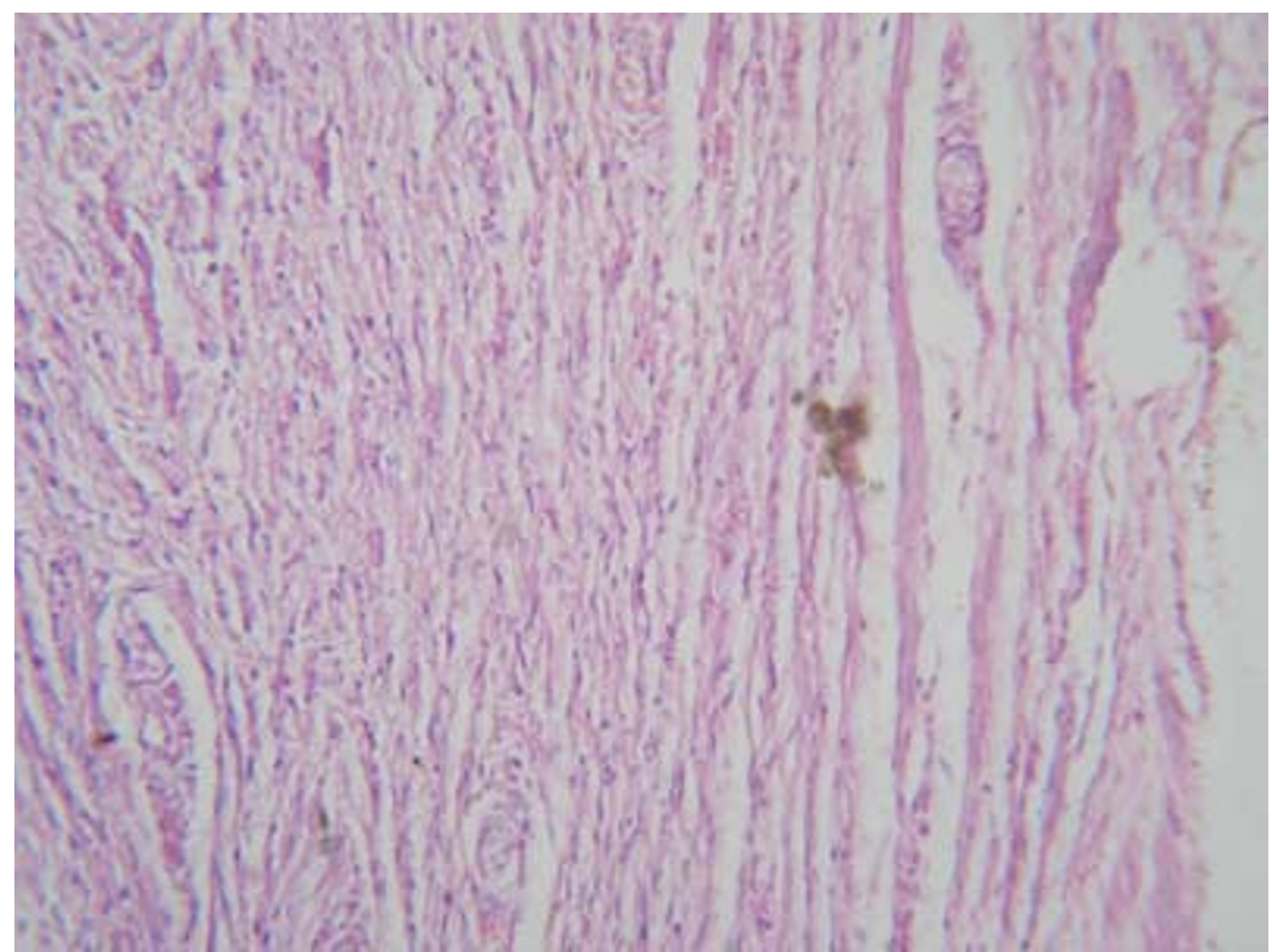

Figure 2

Photomicrograph of tunica albuginea of control subject showing that it consists of collagen fibers arranged circularly and longitudinally (hematoxylin and eosin $\times 400$ ).

trap the blood within the penis. The loss of this venoocclusive function leads to leakage of blood from the penis with a resulting impotence [8-11]. The TA, being composed mainly of collagen fibers, is relatively noncompliant. It occludes the penile venous outflow through compression of the subtunical venular plexus and the perforating emissary veins passing through it. The integrity of the fibroelastic tissue of the TA and CC apparently plays a significant role in the erectile process [12].

\section{A concept on the pathogenesis of venogenic ED}

Venogenic ED is considered to result from an improperly functioning occlusion mechanism $[13,14]$. Investigations lay stress on the role of the TA in the venous occlusion mechanism of the penis during erection $[3,8,9,14]$. In the current study, the TA collagen was found degenerated and atrophic and this probably leads to subluxation and flop- piness of the TA as a tube surrounding the penile corporal tissue. It appears that the subluxated TA, during erection, fails to effect compression of both the subtunical venular plexus and the emissary veins passing through it. Failure of occlusion of the penile venous outflow presumably leads to venous leakage during erection and seems to explain the ED in these patients.

Furthermore, under normal physiologic conditions, the TA is responsible for morphologically shaping the penis during erection. The collagenous structure gives the TA a textile nature which firmly supports the penile architecture during penile tumescence. This TA textile nature, with its circularly and longitudinally oriented collagen fibers lends the TA an adaptability to adjust its length and breadth according to the penile status, whether flaccid or erected. Due to their inelasticity, the collagen fibers limit 


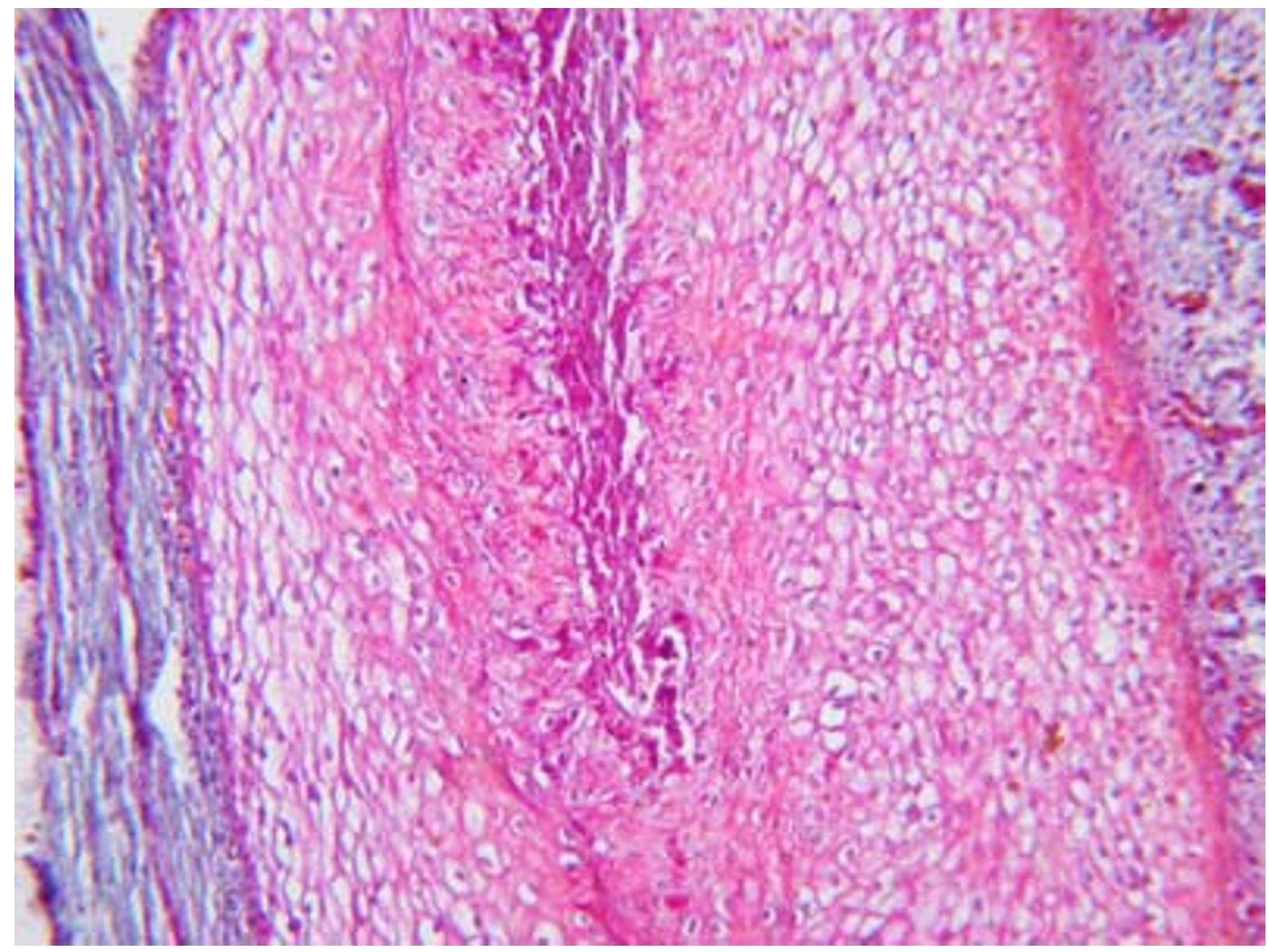

\section{Figure 3}

Photomicrograph of tunica albuginea of a patient with venogenic erectile dysfunction showing degeneration and atrophy of the collagen fibers (Masson's trichrome stain $\times 400$ ).

excessive tunical stretch during penile tumescence. This mechanism prevents tunical subluxation and floppiness which may result from repeated penile tumescence which occurs during the sexual life. Meanwhile, an atrophic subluxated TA would not only disrupt the "venous-leak proof" effect of the TA but disturb the solidity of the erected penis during the process of vaginal penetration and thrusting.

It may be argued that the TA changes are the result of venous leakage. However, this does not seem to be the case since the TA rigidity is claimed to act for prevention of venous lelakage during erection $[8,9,13,14]$. Therefore, although it appears inappropriate that venous leakage should lead to tunical subluxation and floppiness, this possibility cannot be excluded.

Investigators reported a significant decrease in elastic fibers in the TA of impotent patients in comparison to a con- trol group [15]. A reduction of the TA elastic fibers is likely to produce disorders in the arrangement of collagen fibers $[16,17]$. As a matter of fact, electron microscopy revealed severe myopathic, fibrotic changes in the penile tissue [18].

The possible etiology of the atrophic subluxated TA needs to be discussed. The TA consists of collagen and thus may be involved in the pathology of collagen diseases. However, none of the patients had any of these conditions. Aging may affect the TA integrity, but the studied subjects were middle-aged. The history and investigative results of the patients have shown that they had no relevant pathological conditions nor were under drug regimens that may cause ED. However, a recent study has shown that androgen administered to patients with ED due to VED has improved erection in some, but not in all patients [19]. The investigators suggested that penile tissue remodeling is the mechanism that is presumably responsible for correc- 


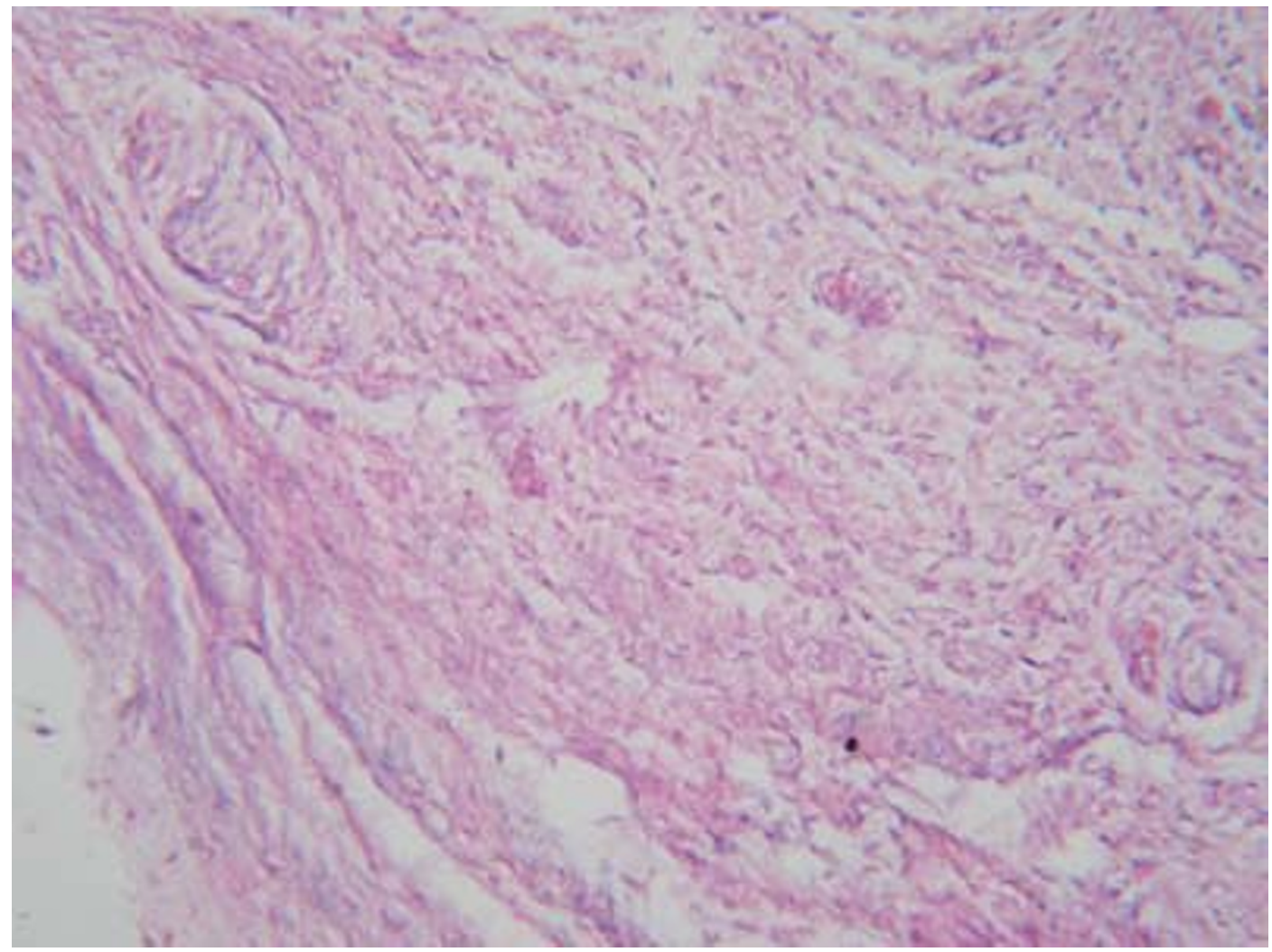

\section{Figure 4}

Photomicrograph of tunica albuginea of a patient with venogenic erectile dysfunction showing fragmentation of collagen fibers (hematoxylin and eosin $\times 400$ ).

tion of the VED by androgen treatment. In view of these factual aspects, we hypothesize that collagenous degeneration and atrophy could be a primary pathologic condition affecting the TA.

A limitation of the study is that the cohort of the patients is not homogeneous for their characteristics. It was difficult to convince healthy subjects to have a biopsy taken from their penile TA. Therefore we seized the opportunity to take the TA biopsy from healthy subjects with normal erection during operative interference; this selection did not effect the results.

\section{Conclusion}

The study has shown that during erection, the ICP of patients with VED was significantly lower than that of the controls. Furthermore, the collagen fibers of the TA exhibited degenerative and atrophic changes that presumably lead to TA subluxation and floppiness. These TA changes seem to explain the cause of the lowered ICP of the patients during erection which apparently results from loss of the TA veno-occlusive mechanism. The cause of atrophic changes and subluxation of the TA needs to be studied.

\section{Abbreviations}

VED, venogenic erectile dysfunction; CC, corpora cavernosa; TA, tunica albuginea ICP, intracorporal pressure;

\section{Competing interests}

The author(s) declare that they have no competing interests. 


\section{Authors' contributions}

AS carried out the study design, data collection, statistical analysis, data interpretation and preparation of manuscript. IA participated in data collection and analysis and literature search. OE participated in data collection, statistical analysis and literature search. AAS participated in data collection and preparation of the manuscript. All authors read and approved the final manuscript.

\section{Acknowledgements}

We thank Margot Yehia for assisting in preparing the manuscript.

\section{References}

I. Lue TF: Physiology of penile erection and pathophysiology of erectile dysfunction and priapsim. In Campbell's Urology 7th edition. Edited by: Walsh PC, Retik AB, Vaughan ED, Wein AJ. Philadelphia: WB Saunders co; 1998: I I57-II79.

2. Carrier S, Brock G, Kour NW, Lue TF: Pathophysiology of erectile dysfunction. Urology 1993, 42:468-468I.

3. Rajfer J, Rosciszewski A, Mehringer M: Prevalence of corporal venous leakage in impotent men. J Urol 1988, 140:69-7I.

4. Metz P, Ebbehoj J, Uhrenholdt A, Wagner G: Peyronie's disease and erectile failure. J Urol 1983, I 30: I I03-1 I 04.

5. lacono F, Barra S, DeRosa G, et al.: Microstructural disorders of tunica albuginea in patients affected by Peyronies's disease with or without erection dysfunction. J Urol 1993, I 50:1806-1809.

6. Dalkin BL, Carter MF: Venogenic impotence following dermal graft repair for Peyronie's disease. J Urol 1991, 1 46:849-85 I.

7. Lewis R: Surgery for erectile dysfunction. In Campbell's Urology 7th edition. Edited by: Walsh PC, Retik AB, Vaughan ED, Wein AJ. Philadelphia: WB Saunders Co: $1215-1235$.

8. Fournier GR, Jueneman K, Lue TF, et al:: Mechanisms of venous occlusion during canine penile erection: an anatomic demonstration. J Urol 1987, 137:163-167.

9. Montague DK, Lakin MM: False diagnosis of venous leakimpotence. J Urol 1992, 148: I48-149.

10. Saenz de Tejada I: Molecular mechanisms for regulltion of penile smooth muscle contractility. Int J Impot Res 2002, I 4(I suppl):S6-10.

II. Fuchs AM, Mewhringer CM, Rajfer J: Anatomy of penile venous drainage in potent and impotent men during cavernosography. J Urol 1989, I 41:13532-1356.

12. Rajfer J, Rosciszewski A, Mewhringer M: Prevalence of corporeal venous leakage in impotent men. J Urol 1988, I 40:69-71.

13. Fitzpatrick TJ: Penile intercommunicating venous valvular system. J Urol 1982, I 27: 1099-II00.

14. Ebbehoj J, Wagner G: Insufficient penile erection due to abnormal drainage of cavernous bodies. Urology 1979, I3:507-5 I0

15. lacono F, Barra S, de Rosa G, Boscaino A, Lotti T: Microstructural disorders of tunica albuginea in patients affected by impotence. Eur Urol 1994, 26(3):233-239.

16. lacono F, Barra S, Cafiero G, m Lotti T: Scanning electron microscopy of the tunica albuginea of the corpora cavernosa in normal and impotent subjects. Urol Res 1995, 23(4):22 I-226.

17. Akkus E, Carrier S, Baba K, Hsu GL, Padma-Nathan H, Nunes L, Lue TF: Structural alterations in the tunica albuginea of the penis: impact of Peyronie's disease, ageing nd impotence. $\mathrm{Br} J$ Urol 1997, 80:190.

18. Liu LC, Huang CH, Huang YL, Chiang CP, Chou YH, Liu LH, Shieh SR, Lu PS: Ultrastructural features of penile tissue in impotent men. BrJ Urol I993, 72(5Pt I):635-642.

19. Yassin AA, Saad F, Traish A: Testosterone undecaonoate restores erectile function in a subset of patients with venous leakage: a series of case reports. J Sex Med 2006, 3:727-735.

\section{Pre-publication history}

The pre-publication history for this paper can be accessed here: http://www.biomedcentral.com/1471-2490/7/14/prepub

Publish with Bio Med Central and every scientist can read your work free of charge

"BioMed Central will be the most significant development for disseminating the results of biomedical research in our lifetime. "

Sir Paul Nurse, Cancer Research UK

Your research papers will be:

- available free of charge to the entire biomedical community

- peer reviewed and published immediately upon acceptance

- cited in PubMed and archived on PubMed Central

- yours - you keep the copyright
BioMedcentral 